\title{
Nudging pro-environmental behavior: evidence from a web experiment on priming and WTP
}

This is the peer reviewed version of the following article:

Original:

Bimonte, S., Bosco, L., Stabile, A. (2020). Nudging pro-environmental behavior: evidence from a web experiment on priming and WTP. JOURNAL OF ENVIRONMENTAL PLANNING AND MANAGEMENT, 63(4), 651-668 [10.1080/09640568.2019.1603364].

Availability:

This version is availablehttp://hdl.handle.net/11365/1075132

since 2021-03-15T13:13:28Z

\section{Published:}

DOI:10.1080/09640568.2019.1603364

Terms of use:

Open Access

The terms and conditions for the reuse of this version of the manuscript are specified in the publishing policy. Works made available under a Creative Commons license can be used according to the terms and conditions of said license.

For all terms of use and more information see the publisher's website.

(Article begins on next page) 


\title{
Nudging pro-environmental behavior: evidence from a web experiment on priming and WTP
}

\author{
Salvatore Bimonte, Luigi Bosco, and Arsenio Stabile
}

\section{QUERY SHEET}

This page lists questions we have about your paper. The numbers displayed at left are hyperlinked to the location of the query in your paper.

The title and author names are listed on this sheet as they will be published, both on your paper and on the Table of Contents. Please review and ensure the information is correct and advise us if any changes need to be made. In addition, please review your paper as a whole for typographical and essential corrections.

Your PDF proof has been enabled so that you can comment on the proof directly using Adobe Acrobat. For further information on marking corrections using Acrobat, please visit http://journalauthors.tandf.co.uk/production/acrobat.asp; https://authorservices.taylorandfrancis.com/how-to-correct-proofs-with-adobe/

The CrossRef database (www.crossref.org/) has been used to validate the references.

\section{AUTHOR QUERIES}

Q1 Please check whether the author names (first name followed by last name) and affiliations are correct as presented in the proofs.

Q2 Please provide the publisher location for reference "Bowles (2016)".

Q3 Please provide missing DOI number for references "Buchanan and Stubblebine (1962), Clarke et al. (1999), Schorn and Maurhart (2009), and Weingarten et al. (2016)".

Q4 The reference "Weingarten et al. 2016" is listed in the references list but is not cited in the text. Please either cite the reference or remove it from the references list. 


\title{
Nudging pro-environmental behavior: evidence from a web experiment on priming and WTP
}

\author{
Salvatore Bimonte ${ }^{\mathrm{a}}$, Luigi Bosco ${ }^{\mathrm{a}}$ and Arsenio Stabile ${ }^{\mathrm{b}}$ \\ ${ }^{a}$ Department of Economics and Statistics, University of Siena, Siena, Italy; ${ }^{b}$ Department of \\ Business and Law, University of Siena, Siena, Italy
}

(Received 22 November 2018; final version received 31 March 2019)

\begin{abstract}
Investigations on state-dependent and endogenous preferences have gained momentum. There is now abundant empirical literature on whether, and how, external stimuli influence or predict people's behavior and appraisals. In recent decades, attempts have been made to enlarge this strand of research to determine whether "nudging" may help in managing environmental problems and boosting social preferences. Following this line of investigation, we describe a web experiment to analyze the impact of priming on environmental and ethical attitudes and willingness to pay (WTP) for environmental protection. We found that while priming does make pro-environmental attitudes more salient, its frame affects the probability of WTP a premium for environment-friendly goods and the size of the premium. Unlike other authors, we used a visual priming technique based on a short video cartoon about a smartphone lifecycle.
\end{abstract}

Keywords: priming; gain-loss frame; environmental attitudes; willingness to pay

\section{Introduction}

Environmental degradation and exploitation of natural resources are impairing the planet's wholeness and its capacity to support life and human development. Environmental management and conservation should be the major concern of any government that has social welfare as a major goal.

Many policies and instruments towards more sustainable growth have been studied and implemented. Most are of the technical type ${ }^{1}$ (i.e. fines, taxes, subsidies). Such policies aim to modify firm and consumer behavior and/or to foster environmental technical innovations by changing their economic incentives. Very little attention has been paid to non-technical tools that aim to modify people's behavior by changing their preferences rather than incentives. This depends on the traditional economic view that preferences are molded by a person's idiosyncratic characteristics, which are assumed to be exogenous and given.

\footnotetext{
Corresponding author. E-mail: Luigi Bosco luigi.bosco@unisi.it

1“A technical solution may be defined as one that requires a change only in the techniques of the natural sciences, demanding little or nothing in the way of change in human values or ideas of morality" (Hardin, 1968 , 1243). Coherently, a non-technical solution occurs only when it generates changes in human values or beliefs.
} 
This standard hypothesis seems counterfactual. It contradicts the huge expenditure of firms in advertising and marketing. It also appears unsatisfactory and limiting from a theoretical point of view, since it implies that preferences cannot be influenced by beliefs and external stimuli, while there is now a growing body of literature arguing that preferences can be state-dependent and endogenous (Bowles 2016; Bowles and Polanía-Reyes 2012, among the others). The "psychological properties of preferences" have important economic and social implications (Fehr and Hoff 2011). Indeed, if preferences are at least partially endogenous and editable, innovative economic policies become available.

This aspect has been widely investigated by social psychologists and behavioral economists. According to Thaler and Sunstein (2008), people are either "Econs" or "Humans", i.e. Homo economicus (rational people) and Homo sapiens (real people). They argue that while the former respond primarily to incentives, the latter are also influenced by nudges. These stimuli affect behavior because people's judgments and choices are the results of intuitive (System 1) and deliberate (System 2) thought (Kahneman 2011). According to these authors, many of our choices are guided or influenced by System 1, which is based on associative memory, automatically and often unconsciously driving the heuristics of our choices and judgments.

Many experiments have investigated whether and how external stimuli influence or predict individual behavior and assessment (Dennis et al. 2015). Most of these studies focused on the impact of nudging on individual willingness to pay (WTP) (Koçaş and Dogerlioglu-Demir 2014). In recent decades, increasing awareness of environmental problems has given rise to a strand of research aimed at investigating whether "nontechnical" instruments can be useful for promoting more sustainable development. In particular, attention has been dedicated to priming as a way of affecting social preferences, especially the perceived value of a public good (Clarke et al. 1999) or WTP for environmental quality (Li et al. 2017).

Following this line of investigation, we set out to shed new light on how "unconventional" policy instruments can help in pursuing environmental goals. Exploiting the current development and spread of social networks and media, we conducted a web experiment to evaluate whether priming affects individual WTP for environmental protection. Unlike most similar studies, it used a visual priming technique based on a short video story. The story is about a smartphone lifecycle.

According to UNEP, e-waste is one of the fastest growing waste streams in developed and developing countries. Our experiment tested the effect of priming on WTP for a recyclable smartphone. To design the most effective nudge in terms of environmental attitudes, it conducted a three-sample experiment in which two samples were primed with differently framed visual messages: "degraded" vs. "conserved" environment. ${ }^{2}$

Environmental degradation may be discussed in terms of the positive and negative consequences of undertaking or not undertaking mitigation actions (Spence and Pidgeon 2010). Both frames should modify individual behavior and the likelihood to opt for mitigation, but investigating which information frame is more effective is of interest. According to Prospect Theory, a loss produces higher disutility (discomfort) than the utility yielded by a commensurate gain. While this is normally tested in terms

\footnotetext{
${ }^{2}$ The three short videos used in our web experiment are available online: control group (https://rive.google. com/file/d/1_6PZsp0DBVJT9KmxDLAUzzzaYGVNcLwT/view), positive priming (https://drive.google.com/ file/d/1-QXop5GhiPeLSwm5pvjuhN_n4iz_Pfwv/view), negative priming (https://drive.google.com/file/d/ 1yATTtuBVAOAVUPhFGzCih2BVQ8c_PFpJ/view).
} 
of WTA and WTP disparity (Sayman and Öncüler 2005), we tried to grasp it by means of WTP alone in order to avoid the bias induced by monetary assessments (pay rather than accept) (Irwin 1994).

People were, therefore, asked to watch a very short video and then to complete a questionnaire. In the authors' opinion, the first and main perception we have of the state of our environment is aesthetic and visual. Unlike value-laden words and scramble games requiring specific expertise to understand (Andersson et al. 2017), visual priming makes it possible to convey different types of environmental quality/settings directly and to test the impact of negative and positive frames on individual behavior. Our hypothesis is that a conserved natural environment makes us aware of what we would lose if we do not implement sustainable policy (the hold-paradise option). On the contrary, a contaminated and degraded setting suggests that sustainable policy is needed to improve environmental quality (the escape-hell option). In line with expectations, priming made pro-environmental attitudes more salient and increased the probability of WTP something for environmental protection. Moreover, according to the loss aversion and endowment effect (Kahneman and Tversky 1979), our experiment confirmed that a nudge reminding people what they are losing - the environment and quality of life - is more effective than a nudge focusing on pollution abatement, i.e. recovering the "paradise lost".

The paper is organized as follows: in the next section, we briefly review the literature on priming and pro-social behavior, focusing on environmental attitudes. The third section presents data, method, and results. The remaining sections are devoted to discussing results and drawing some preliminary conclusions.

\section{Priming and social choice: an essential literature review}

In the famous experiment known as the Florida effect, the psychologist John Bargh asked two groups of students to compose four-word sentences from a set of five words. For one of the two groups, the set was composed of words linked to stereotypes of old age. After they had completed the task, participants were asked to move to another office for another experiment. Students primed with words regarding old age walked to the other office significantly more slowly than the others (Bargh et al. 1996). Since this pioneering work, priming techniques have been used by social psychologists and behavioral economists to show that preferences can also be shaped by choice architecture and social environment (for the critical survey, see Bargh 2006; Cohn et al. 2016; Molden 2014).

Many experiments have been carried out to demonstrate that priming affects people's behavior and choices. The results are statistically significant and robust. Vohs (2015) did a meta-analysis on a number of experiments from 18 countries and showed that people primed with money were less prosocial, eschewed interdependence and behaved more competitively than neutral primes. Albeit in reverse, the priming effect was confirmed by Shariff et al. (2016) who analyzed 93 studies and found that religious priming had robust effects on prosocial and various other outcomes. They also found that the effects of religious priming depended on people's religious beliefs, i.e. it did not work with non-religious participants.

Many of these experiments used value-laden words or scramble games to cue or nudge participants (for a review, see Andersson et al. 2017). Another frame used in such studies was "watchful eyes". Haley and Fessler (2005) conducted a Dictator 
Game and showed that displaying eye-like stimuli on a computer substantially increased the probability of cooperation and the size of donations by participants. Rigdon et al. (2009) reached similar results.

Such experiments have been replicated with different results, although, in general, the effect of watching-eye experiments modeled in a Dictator Game framework offers robust results. Nettle et al. (2013) reported a meta-analysis of seven studies involving 887 participants and highlighted that while such cues did not give reliable results in terms of mean donations, they did increase the probability of donating something rather than nothing.

Ekström (2012) conducted a natural experiment in a chain of Swedish supermarkets, testing whether the probability of donating the money obtained from recycling cans and bottles increased when a picture of human eyes appeared on the recycling machines. Controlling for fixed effects (store and day), the picture positively affected the sum donated and the effect was stronger when few people visited the store (reputation effect). Unlike the previous study, Schorn and Maurhart (2009) tested the effect of supraliminal priming on prosocial behavior using the concept of honesty. They used three different priming stimuli mirroring the words "honest", "dishonest" and a meaningless control word. The field experiment was performed among people using a toilet at the motorway service area. They found that people primed with the concept of honesty contributed more money than those not primed, while no significant difference emerged between people primed with the word "dishonest" and those primed with the word "honest" or not primed. ${ }^{3}$

Visual priming, using the concept of anchoring, has also been used to appraise the impact on people's WTP for a private good. For example, Dennis et al. (2015) performed an experiment to evaluate whether irrelevant and relevant advertisements affected a person's WTP in an online auction. They found that the bid was higher (lower) when participants were exposed to an advertisement with a high (low) price, irrespective of whether or not the advertisement was relevant to the product. When the auctioned good had a suggested price, advertisements only exerted an effect if they were relevant to the products. Although somewhat different, the experiment conducted by Koçaş and Dogerlioglu-Demir (2014) confirmed these findings. They also found that priming not only affected average WTP but the whole distribution.

Building on these results, attention has also been devoted to priming as a way of dealing with environmental problems and especially of boosting prosocial behavior. While a substantial number of studies using contingent valuation have been carried out to elicit people's WTP and willingness to accept (WTA) in order to preserve an environmental feature (e.g. biodiversity) or to estimate economic values for non-market goods, few studies exist on the effect of priming on WTP and WTA.

A core question addressed by this new line of investigation is whether priming environmental attitudes influence the perceived value of environmental goods. This is a primary question first pursued by social psychologists. They tried to understand whether and how exposure to different types of information (priming) aimed at activating social representations (e.g. traits, goals) affected representations in social judgments and behaviors (Molden 2014). Building on Prospect Theory, another issue this

\footnotetext{
${ }^{3}$ The authors argued that a possible explanation could be ambivalent perceptions of the word dishonest, which could lead some people to process the primes dishonest and honest in similar ways. Using subliminal priming based on value-laden words, Andersson et al. (2017) found no significant effect of priming on donation but a positive effect among those with pre-existing pro-social preferences.
} 
strand of literature tries to address is the impact of positive vs. negative frames on perceived value and prosocial commitments.

Prospect Theory, developed by Kahneman and Tversky, argues that humans, as opposed to Econs, do not always respond rationally to information or act rationally under uncertainty. One of its implications is that the effectiveness of messages may depend on framing. Unlike in standard economic theory, individuals may act differently to identical situations depending on whether the framing is positive (gain) or negative (loss), because people tend to give more weight to loss than to gain.

The results are not homogeneous. In fact, while findings on the effect of priming are quite robust, those on the type of message (positive vs. negative) depend on the experiment and need additional investigation. In a survey carried out in the USA, participants were asked to self-evaluate whether the information provided made them more or less likely to buy organic food. It turned out that the impact of framing on the self-reported likelihood was positive, but the loss-adverse hypothesis was not proved (Gifford and Bernard 2006). Li et al. (2017) obtained different results. They tested WTP for five runoff management practices and found that while priming did not affect the likelihood of bidding, it positively influenced the WTP of participants who placed bids. However, the difference was only statistically significant for those primed with positive framing.

This result somehow confirms the argument of Andreoni (1995), who reported that, contrary to theory, subjects in positive-frame condition were more likely to cooperate than subjects in negative-frame condition. Although incentives were identical in the two frameworks, cooperation in public good provision was perceived to contribute to the well-being of others (positive externality), whereas in the case of a private good with externality, it was perceived to make others worse off (negative externality), i.e. "the warm-glow of creating a positive externality appears to be stronger than the cold-prickle of creating a negative externality" (Andreoni 1995, 2).

This is consistent with Clarke et al. (1999) who conducted a computer-based experiment among university students. They tested the impact of two contextual factors, i.e. social responsibility and editorial priming. Members of the first group were informed that the outcome for the entire group depended on their individual choice, whereas members of the second group were told that the outcome depended on the choices of all participants. Participants were primed with a neutral or strong editorial prime deriding environmental alarmists or informing about the dangers of pollution. The results showed that environmental goods were valued more in the sole than in the shared responsibility scenario, indicating the effect exerted by perceived social responsibility. The assigned value, however, was not affected by priming.

The social responsibility scenario was confirmed by Spence and Pidgeon (2010) who studied whether the way communication about climate change was framed could significantly alter the response of recipients. They framed the same information in terms of gain or loss outcomes and local vs. distant impacts. Other things being equal, they found that gain frames were more effective than loss frames in inducing positive attitudes towards climate change mitigation. Positive responses could also be obtained by focusing on the social impacts of climate change mitigation rather than on personal/private consequences.

Following this line of investigation, we conducted an experiment to test the impact of frames on people's WTP a price premium for a smartphone with a high level of recyclability. Instead of scramble games or imagery processes involving value-laden words, it exploited a visual account of the life of a smartphone and posed the following hypotheses: 
H1: Priming affects people's environmental attitudes and awareness.

H2: When environmental goods are involved, perceived loss (deterioration - holdparadise option) is assigned more weight than perceived gain (decontamination recovering the paradise lost option).

\section{Study method and results Participants and procedure}

A total of 181 subjects (96 men and 85 women) were recruited using Facebook, Instagram, and Twitter and invited to participate in a survey on smartphones and multimedia cartoons by connecting to a web link. The data were collected by an anonymous online survey using Google Forms. Google Forms randomly assigned participants to three groups. Participants were told that they first had to watch a short video and then fill in a questionnaire.

In order to be consistent with the title of the survey, the first part of the questionnaire included some questions on multimedia cartoons that had no relation to the goal of our research. The second section was on smartphones and individual attitudes. Respondents were asked to score various factors influencing their decision when buying a smartphone. Scores were on a 5-point scale, ranging from 1 (not at all) to 5 (very important). Respondents were also asked, other things being equal, whether they were willing to pay a higher price for an ecological smartphone (highly recyclable) and if so, how much. The third part concerned socioeconomic characteristics. Finally, following Bargh and Chartrand (2014), we asked respondents whether they had noticed anything specific during the survey and whether they thought the video influenced their answers. The purpose of this question was to exclude any conscious or intentional strategies, i.e. subjects who were aware of the stimulus.

While the questionnaire was the same for all participants, the videos were not. They consisted of a sequence of black and white cartoons telling the lifecycle of a smartphone. Two groups were primed. Priming consisted of an additional color cartoon in both cases reproducing a person taking a picture with a smartphone. In one case (nature priming), the cartoon had an uncontaminated landscape in the background, in the other (urban priming), a congested road and some chimneys. In the first case, the video ended with a cartoon showing a recycled smartphone in a shop window, whereas in the second, it showed a smartphone in a dump. In the neutral video, these two cartoons did not appear.

According to Prospect Theory, people's behavior is sensitive to information and the way it is framed. It argues that they value gains less than losses and are therefore less willing to take risks when considering gains than when avoiding losses. In other words, people are risk-averse when considering the potential gain offered by a decision, and risk-seeking when considering the possible loss caused by a decision. Loss frames are therefore more effective when behaviors considered risky are concerned, whereas gain frames are preferred with behaviors considered safe (Banks et al. 1995; Edwards et al. 2001). ${ }^{4}$

\footnotetext{
${ }^{4}$ In health psychology, empirical evidence indicates that loss frames are more effective for encouraging detection behavior and gain frames for encouraging prevention behavior (Rothman et al., 2006).
} 
Our hypothesis was that environmental protection may be better pursued within a loss frame. In our experiment, the natural environment setting is compatible with the prevention option because pro-environment behavior seeks to prevent future degradation or to ensure conservation (avoid a loss). On the contrary, the degraded environment setting is compatible with the cure option, since pro-environmental action may improve environmental quality (obtain a gain), i.e. recover the paradise lost.

Besides avoiding misunderstandings based on the comprehension of words or individual differences in scrambling ability, our experiment also avoided the problem of defining personal perspectives on risk and safety. By testing both frames in terms of WTP, it avoided bias due to monetary assessments (pay rather than accept) (Irwin 1994).

Before starting the experiment, a pre-test was conducted among university students. Several students were invited to take part in an off-line experiment. The pre-test did not reveal any particular difficulties and nobody noted a relationship between the video and the questionnaire. This confirmed that none of the students was aware of the stimulus.

\section{Descriptive statistics and method}

In view of the aim of the study, two distinct analyses were carried out. We first performed a descriptive investigation of the three samples. We then did an independent test for significant differences between groups. Due to sample characteristics and the type of variables (categorical or ordinal) the $\chi^{2}$ or Kruskal-Wallis tests were used. Finally, logit and ordered logit models were developed to identify any correlation between priming frames and self-reported environmental attitude and WTP, which were treated as response variables. In order to test the robustness of the results and the role of other factors that are normally considered to affect individual attitudes, we also included other relevant determinants in the models. The data were analyzed using STATA software.

The total sample consisted of 181 individuals; $47 \%$ were females and $53 \%$ males; aged 18 to 54 years $(M=28.3 S D=9.5)$. The youth of the participants was due to the type of experiment, a web-survey. Individuals were randomly assigned to three groups, two of which were primed. No systematic differences were detected in the structural characteristics of the groups (samples) (see Table 1). ${ }^{5}$ All participants declared that they had a smartphone. The groups did not show any significant dissimilarity in terms of spending habits: primed and non-primed subjects normally changed their phone every 3 years (median) and, on average, paid a similar price for it.

\section{The effect of priming}

In order to test the impact of priming, we analyzed differences in response variables between groups. Besides testing for differences in pro-environment attitude variables, we also investigated other aspects that may influence individual choices but that, in the authors' opinion, had no relationship with the frame. Table 2 shows the results.

\footnotetext{
${ }^{5}$ The only significant difference emerged for income. However, these data have to be taken with caution because $39 \%$ of participants did not answer the question. Data may also be non-homogeneous because the question could refer to own or family monthly income.
} 
Table 1. Main sample characteristics (descriptive statistics).

\begin{tabular}{|c|c|c|c|c|}
\hline \multirow[b]{2}{*}{ Variables } & \multicolumn{3}{|c|}{ Groups } & \multirow{2}{*}{$\begin{array}{c}\text { Test } \\
p \text {-value }\end{array}$} \\
\hline & Neutral $(n=60)$ & Urban $(n=60)$ & Nature $(n=61)$ & \\
\hline \multicolumn{5}{|l|}{ Gender } \\
\hline Male & $48.3 \%$ & $58.3 \%$ & $52.4 \%$ & 0.544 \\
\hline Female & $51.7 \%$ & $41.7 \%$ & $47.5 \%$ & \\
\hline Age (mean) & $29.8(S D=10.38)$ & $27.3(S D=8.14)$ & $27.8(S D=9.06)$ & 0.3013 \\
\hline $\begin{array}{l}\text { How often changed } \\
\text { phone? (median, years) }\end{array}$ & 3 & 3 & 3 & 0.3603 \\
\hline Price (mean, euros) & $365(S D=107.5)$ & $342(S D=129.2)$ & $329(S D=100.6)$ & 0.2070 \\
\hline \multicolumn{5}{|l|}{ Education } \\
\hline Lower secondary & $8.3 \%$ & 10 & 4.92 & 0.77 \\
\hline Upper secondary & $50 \%$ & $50 \%$ & $47.5 \%$ & \\
\hline University (Bachelor) & $28.3 \%$ & $31.7 \%$ & $39.3 \%$ & \\
\hline Master & $13.3 \%$ & 8.33 & 8.2 & \\
\hline \multicolumn{5}{|l|}{ Work status } \\
\hline Student & $53.3 \%$ & $55 \%$ & $63.9 \%$ & 0.434 \\
\hline Employed & $40 \%$ & $41.7 \%$ & $27.9 \%$ & \\
\hline Not employed & $6.7 \%$ & $3.3 \%$ & $8.2 \%$ & \\
\hline
\end{tabular}

Table 2. Between-group analysis: descriptive statistics (sample, $n=181$ ).

Factors influencing choice of smartphone $(1=$ not at all;

$5=$ very important)

Kruskal-Wallis

Single items

(median value)

Urban Natural $\quad p$-value

Price

Advice from friends

Advertising

Ethical and environmental characteristics

WTP

$\begin{array}{ccc}\text { Neutral } & \text { Urban } \\ 3 & 3 & 2\end{array}$

40.1048

$2 \quad 2$

$2 \quad 2$

$1 \quad 1 \quad 2$

0.1433

$2 \quad 2$

2

0.3562

2

0.0001

Other things being equal, would you

No Yes

Reserve price

What is the maximum difference you would be WTP? (median value)

The first part of Table 2 indicates the importance, on a 5-point scale, that respondents assigned to certain factors when purchasing a smartphone. Significant differences only emerged with respect to the ethical and environmental characteristics of the smartphone $(p=0.0001)$, which was one of the variables we used to test respondents' pro-environment attitudes. The other variables were WTP a higher price for an eco-friendly smartphone and the maximum premium one would be willing to pay for an eco-friendly smartphone. For both variables, significant differences emerged between groups ( $p=0.008$ and 0.0099 , respectively). With respect to the reserve price, although all groups had the same median value, we detected dissimilarities in the distribution (Table 3). 
These results confirm that priming affected individual response. However, on closer examination, the results were not so straightforward: there were differences between loss and gain frames. This was shown by the differences between pairs of groups (Table 4). Regarding the influence of ethical and environmental values on purchase choice, the results confirm that priming did affect the subjects' environmental consciousness. On the contrary, with regard to WTP and reserve price, i.e. maximum premium, it emerged that significant differences only arose with respect to natural priming (loss adverse), compared to control (neutral) and urban-primed groups.

Having detected these differences in the responses, we tested for the type of impact that priming had on our three variables, i.e. we tested whether priming boosted a proenvironmental attitude, and in particular, whether loss frames were more effective when dealing with behaviors considered risky. This we did by logit and ologit analysis. The results are shown in Tables 5-7.

In these models, the reference variables are those indicating a pro-environmental attitude, i.e. the importance given to ethical and environmental aspects when buying a smartphone (Table 5), WTP a higher price for an eco-friendly smartphone (Table 6) and the maximum premium (as a percentage) respondents were willing to pay for such a smartphone (Table 7). The covariate coefficient indicates the expected change in the response variable implied by a unit increase in the predictor (i.e. moving from one level to another of the variable) (odds ratio). Specifically, a coefficient greater (less) than 1 means that a unit change in the independent variable increases (decreases) the likelihood of obtaining a higher score for the dependent variable, quantified by the coefficient (Long and Freese 2006).

For each reference variable, we show four estimates testing the link between priming and pro-environmental attitude. We started with a simple regression of the effects of priming frames on reference variables. In the first case, we observed an effect of priming on environmental attitude, both for gain (urban) and loss frames (nature), though stronger in the latter case. The significant positive association did not seem driven by other factors. In fact, the results did not change substantially when other important control variables were added (models 2, 3 and 4). The positive effect of priming increased from model 1 to model 4 , especially for nature priming, and the terms remained robust in all specifications. Model 4 highlighted that gender and a high level of education also have a positive impact, while the impact of smartphone price is almost zero, though highly significant in all estimates. ${ }^{6}$ These results are in line with those of other studies (Clarke et al. 1999).

As expected, the second and third estimates (Tables 6 and 7) gave slightly different results. While confirming the irrelevance of a number of variables, the robustness of estimates and the same behavior of the coefficients in the different models, they showed that only the nature framing had an effect on WTP. The loss (nature) frame considerably boosted the probability of WTP something for an eco-friendly smartphone. It also affected the percentage premium on the price that individuals were willing to pay. Among those willing to pay something, the probability of offering a higher price more than doubled. In both models, gender and smartphone price turned out to be significant. However, as before, the impact of the latter was almost zero.

\footnotetext{
${ }^{6} \mathrm{We}$ venture to say that smartphone price could be a proxy for purchasing power. We did not consider income because as stated earlier, 39\% of participants did not answer this question and it is a sensitive variable that can give rise to untruthful responses.
} 
Table 3. Between-group analysis: max difference subjects were WTP (frequencies).

\begin{tabular}{lccc}
\hline Group & Neutral & Urban & Nature \\
\hline $5 \%$ & $40 \%$ & $39.1 \%$ & $18.2 \%$ \\
$10 \%$ & $35 . \%$ & $39.1 \%$ & $34.6 \%$ \\
$15 \%$ & $12.5 \%$ & $10.9 \%$ & $25.4 \%$ \\
$20 \%$ & $7.5 \%$ & $8.7 \%$ & $16.4 \%$ \\
Over $20 \%$ & $5 \%$ & $2.2 \%$ & $5.4 \%$ \\
\hline
\end{tabular}

Table 4. Between-group analysis (Wilcoxon-Mann-Whitney).

\begin{tabular}{lccc}
\hline Items $(p$-value $)$ & Neutral vs. Urban & Neutral vs. Natural & Urban vs. Natural \\
\hline $\begin{array}{l}\text { Ethical and environmental } \\
\text { characteristics }\end{array}$ & 0.0003 & 0.0000 & 0.0587 \\
WTP $^{\mathrm{a}}$ & 0.2242 & 0.0017 & 0.0457 \\
Reserve price & 0.8938 & 0.0130 & 0.0044 \\
\hline
\end{tabular}

${ }^{\mathrm{a}}$ Two-sample test of proportions.

\section{Discussion}

Our findings confirmed both our hypotheses ( $H 1$ and $H 2$ ), namely that priming makes pro-environmental attitudes more salient and frame affects the probability of WTP for environmental protection and the size of the price one is willing to pay.

The mechanism of priming is well known: exposing people to stimuli activates associative memory and can make a particular attitude (in this case, a pro-environmental attitude) more salient and therefore more relevant to the decision to be made (Akerlof and Kranton 2000). In our case, the respondents were subject to two pairs of visual unconscious stimuli: an uncontaminated landscape and a happy recycled phone in the shop window in the natural frame; a degraded landscape and a sad phone in a dump in the urban frame. The control group received no stimuli.

When choosing a phone, consumers evaluate different items (e.g. price, technical characteristics and the intrinsic attractiveness of the brand, which are signals of phone quality and also reflect some form of social pressure). If consumers are not totally selfish and have social preferences, they also consider the ecological footprint of the phone. Our results show that when primed, people tend to ascribe more importance to the ecological content of the good (Table 4). Our results, therefore, confirm that a significant number of people would be willing to take environmental problems into account when buying a mobile phone if stimulated to do so.

The regression results confirmed that exposure to priming significantly increased the probability of an ethical and pro-environmental attitude (Table 5): the coefficients also maintained their size and significance when some relevant control variables were added to the regression. The effect, therefore, appears quite robust. However, only the loss frame (nature priming) modified the probability of paying an ethical premium when buying a phone (Table 6) and the size of the premium (Table 7). As discussed below, the frame of the priming was not neutral.

It is no surprise that few control variables in the regressions were significant: the price paid for the last phone bought, and gender, were the most interesting. The first 
Table 5. Ethical and environmental awareness: ologit regression (odds ratio).

\begin{tabular}{lcccc}
\hline Variables & $(1)$ & $(2)$ & $(3)$ & $(4)$ \\
\hline Urban priming & $3.546^{* * *}$ & $3.105^{* * *}$ & $3.340^{* * *}$ & $3.884^{* * *}$ \\
& $(1.236)$ & $(1.099)$ & $(1.194)$ & $(1.424)$ \\
Nature priming & $6.652^{* * *}$ & $6.000^{* * *}$ & $6.664^{* * *}$ & $7.624^{* * *}$ \\
& $(2.382)$ & $(2.172)$ & $(2.446)$ & $(2.846)$ \\
Smartphone price & & $0.994^{* * *}$ & $0.994^{* * *}$ & $0.994^{* * *}$ \\
& & $(0.00136)$ & $(0.00140)$ & $(0.00140)$ \\
Upper secondary & & 0.864 & 1.043 \\
& & & $(0.474)$ & $(0.604)$ \\
University degree & & & 1.359 & 1.693 \\
& & & $(0.757)$ & $(1.001)$ \\
Master degree & & & $\left(2.380^{* *}\right.$ & $6.501^{* * *}$ \\
& & & & $(4.611)$ \\
Age & & & & 1.017 \\
& & & & $(0.0166)$ \\
Female & & & $2.133^{* * *}$ \\
& & & $0.113^{* * *}$ & $(0.618)$ \\
Constant cut1 & 0.960 & $0.109^{* * *}$ & $(0.0828)$ & $(0.327$ \\
& $(0.238)$ & $(0.0621)$ & 0.736 & 2.268 \\
Constant cut2 & 0.653 & $(0.526)$ & $(2.197)$ \\
& $(1.435)$ & $(0.359)$ & $3.920^{*}$ & $12.95^{* * *}$ \\
Constant cut3 & $23.14^{* * *}$ & $3.285^{* *}$ & $(2.812)$ & $(12.66)$ \\
& $(7.898)$ & $(1.830)$ & $14.57^{* * *}$ & $50.59^{* * *}$ \\
Constant cut4 & $79.65^{* * *}$ & $11.97^{* * *}$ & $(11.20)$ & $(51.65)$ \\
& $(35.88)$ & $(7.410)$ & 181 & 181 \\
Observations & 181 & 181 & 0.119 & 0.136 \\
Pseudo $R^{2}$ & 0.0600 & 0.0965 & 61.04 & 69.70 \\
LR $\chi^{2}$ & 30.88 & 49.65 & & \\
\hline & & & &
\end{tabular}

SE values in parentheses.

${ }^{* * *} p<0.01,{ }^{* *} p<0.05,{ }^{*} p<0.1$.

was always significant, although slightly different from one. ${ }^{7}$ This implies that the higher the price paid for the last phone purchased, the lower the probability of a proenvironmental attitude. If we consider phone price as an indicator of attention to mainstream phone features (high technical characteristics or fashionable brand), this result suggests a trade-off between private and social preferences: the higher the interest for private characteristics the lower the attention for social aspects. However, as we have said, although this effect was statistically significant, it was almost zero.

Unlike the previous variable, in all regressions, the gender effect was significant and not negligible in size. This is consistent with the results of other studies showing that women have relatively stronger environmental concerns and behavior than men (Dietz et al. 2002; Vicente-Molina et al. 2018). Being a female significantly increased the probability of having a pro-environmental attitude, WTP an ethical premium, and the size of the premium. It also indicated that the effect of priming was stronger.

\footnotetext{
${ }^{7}$ These are odds ratios: a coefficient greater (less) than 1 means a higher (lower) probability of obtaining a higher (lower) score for the dependent variable, quantified by the coefficient. This means that a value close to 1 implies no impact.
} 
Table 6. WTP a higher price for an eco-friendly smartphone: logit regression (odds ratio).

\begin{tabular}{lcccc}
\hline Variables & $(1)$ & $(2)$ & $(3)$ & $(4)$ \\
\hline Urban priming & 1.643 & 1.572 & 1.652 & 1.887 \\
& $(0.674)$ & $(0.652)$ & $(0.698)$ & $(0.821)$ \\
Nature priming & $4.583^{* * *}$ & $4.217^{* * *}$ & $4.269^{* * *}$ & $4.854^{* * *}$ \\
& $(2.336)$ & $(2.168)$ & $(2.222)$ & $(2.591)$ \\
Smartphone price & & $0.997^{*}$ & $0.997^{*}$ & 0.997 \\
& & $(0.00160)$ & $(0.00168)$ & $(0.00170)$ \\
Upper secondary & & 1.631 & 1.737 \\
& & & $(1.043)$ & $(1.209)$ \\
University degree & & 2.406 & 2.811 \\
& & & $(1.648)$ & $(2.087)$ \\
Master degree & & & $5.714^{*}$ & $7.207^{*}$ \\
& & & $(5.571)$ & $(7.324)$ \\
Age & & & 1.020 \\
& & & & $(0.0220)$ \\
Female & & & & $2.049^{*}$ \\
& & & 3.049 & $(0.823)$ \\
Constant & & & $(2.606)$ & $(1.178)$ \\
Observations & $(0.548)$ & $\left(3.695^{* * *}\right.$ & 181 & 181 \\
Pseudo $R^{2}$ & 181 & 181 & 0.0940 & 0.117 \\
LR $\chi^{2}$ & 0.0544 & 0.0702 & 17.98 & 22.46 \\
\hline
\end{tabular}

SE values in parentheses.

${ }^{* * *} p<0.01,{ }^{* *} p<0.05,{ }^{*} p<0.1$.

Our findings also confirmed the second hypothesis (H2), showing that nature (loss) frame was much more effective than the urban (gain) frame. The two priming schemes produced different effects. Table 4 shows that while both increased the importance that agents attributed to the ethical and environmental characteristics of the phone, only the natural framework had a significant effect on WTP and on the size of the ethical premium consumers were willing to pay. The agents seemed to behave differently according to the type of stimulus they received. Priming was therefore effective, but the way it was designed also mattered a lot. We could say that both priming stimuli changed the attention paid to environmental problems, but only positive-framed (nature) priming had an effect on WTP. In economic terms, while the urban frame contributed to making "externalities" potentially relevant, the nature frame made them Pareto-relevant. ${ }^{8}$

The regression results support this conclusion. In considering WTP and the amount of the ethical premium, being primed with a positive stimulus (nature priming) significantly increased the probability of paying an ethical premium (Table 6) and of paying a higher premium (Table 7). The results were relatively unaffected by the introduction of the control variables, whereas the effect of urban priming (negatively framed), though positive, was less than that of nature priming and never statistically significant. Urban priming was, therefore, unable to increase the probability of paying an ethical premium when buying a smartphone.

Our results suggest that while both priming mechanisms reminded consumers of the importance of the environmental content of the phone choice, only the positive

${ }^{8}$ For a distinction between relevant and Pareto-relevant externalities, see Buchanan and Stubblebine (1962). 
Table 7. Maximum price premium for an eco-friendly smartphone: ologit regression (odds ratio).

\begin{tabular}{lcccc}
\hline Variables & $(1)$ & $(2)$ & $(3)$ & $(4)$ \\
\hline Urban priming & 0.946 & 0.815 & 0.936 & 1.047 \\
& $(0.379)$ & $(0.332)$ & $(0.384)$ & $(0.434)$ \\
Nature priming & $2.687^{* *}$ & $2.272^{* *}$ & $2.822^{* *}$ & $3.082^{* * *}$ \\
& $(1.044)$ & $(0.889)$ & $(1.149)$ & $(1.264)$ \\
Smartphone price & & $0.996^{* *}$ & $0.996^{* *}$ & $0.996^{* * *}$ \\
& & $(0.00145)$ & $(0.00149)$ & $(0.00151)$ \\
Upper secondary & & 0.391 & 0.675 \\
& & & $(0.257)$ & $(0.499)$ \\
University degree & & 0.457 & 0.778 \\
& & & $(0.305)$ & $(0.585)$ \\
Master degree & & & 1.295 & 2.852 \\
& & & $(1.005)$ & $(2.480)$ \\
Age & & & 1.029 \\
& & & & $(0.0206)$ \\
Female & & & & $1.982^{* *}$ \\
& & & $0.643)$ \\
Constant cut1 & 0.625 & $0.161^{* * *}$ & $0.0832^{* * *}$ & 0.421 \\
& $(0.191)$ & $(0.102)$ & $(0.0699)$ & $(0.512)$ \\
Constant cut2 & $3.147^{* * *}$ & 0.856 & 0.472 & 2.545 \\
& $(1.012)$ & $(0.525)$ & $(0.384)$ & $(3.084)$ \\
Constant cut3 & $8.640^{* * *}$ & 2.451 & 1.383 & $7.734^{*}$ \\
& $(3.128)$ & $(1.513)$ & $(1.114)$ & $(9.401)$ \\
Constant cut4 & $36.72^{* * *}$ & $10.68^{* * *}$ & $6.101^{* *}$ & $35.66^{* * *}$ \\
& $(18.52)$ & $(7.486)$ & $(5.298)$ & $(45.25)$ \\
Observations & 141 & 141 & 141 & 141 \\
Pseudo $R^{2}$ & 0.0259 & 0.0412 & 0.0573 & 0.0755 \\
LR $\chi^{2}$ & 10.31 & 16.42 & 22.85 & 30.12 \\
\hline
\end{tabular}

SE values in parentheses.

$* * * p<0.01,{ }^{*} p<0.05,{ }^{*} p<0.1$.

framework produced a change in their intentions by increasing their WTP. As stated before, this result is consistent with the loss aversion and endowment effect and is in line with a similar result obtained by Spence and Pidgeon (2010).

Another tentative explanation may be based on the conditional cooperation hypothesis of Fischbacher et al. (2001), who showed that in an experimental situation in which a public good has to be financed and people have the chance to free ride, people behave differently according to personality traits and beliefs. They observed three groups of people: unconditional co-operators, who tended to finance the public good irrespective of others' contributions; selfish people, who did not contribute irrespective of others' behavior; conditional co-operators (the most numerous), whose contribution to the public good was positively correlated with their beliefs about the contributions of other people (Chaudhuri 2011).

In our framework, reducing e-waste is a public good that can be financed by paying an ethical premium when acquiring a sustainable phone. If we reasonably assume that among our subjects there are conditional cooperators, we can conclude that they are conditioned differently by the two priming settings. The negative framework - the degraded environment and the sad phone discarded in a dump - conveys the belief 
that other people are not contributing; otherwise, the situation would be better. This can be expected to reduce conditional cooperators' willingness to contribute. On the other hand, the positive framework - a natural environment and a happy recycled phone in the shop window - implies a situation in which most people are considering environmental problems and behaving virtuously, and it increases conditional cooperators' willingness to contribute.

The idea is very simple. Priming makes two different attitudes more salient: environmental awareness and conditional cooperation. In the case of a positive framework, both stimuli go in the same direction and produce the same results, increasing the importance ascribed to phone ethical features and WTP something (an ethical premium) to contribute to the solution. In the case of a negative framework, they go in opposite directions, partially offsetting each other, at least for subjects who are aware of the environmental problem but are only conditional cooperators.

It is not surprising that while there was no significant difference in the importance attributed to environmental features in the two frameworks (first row of Table 4), major differences emerged for WTP (second and third rows of Table 4). WTP and its size are a measure of the contribution that an individual makes to production of the public good. In the urban framework, conditional cooperators do not contribute, since the priming received suggests that others are not contributing. Obviously, this second explanation does not exclude the previously mentioned loss aversion and endowment effects, which can coexist and operate simultaneously.

\section{Concluding remarks}

The present study addressed the intriguing issue of whether beliefs and external stimuli affect people's preferences (Bowles 2016; Bowles and Polanía-Reyes 2012). It demonstrated that, in the case of a smartphone purchase, people's behavior and appraisal of the phone's private and social characteristics were affected by priming and frames. Consistently, it argued that non-technical tools may help in pursuing sustainable development.

Unlike other studies, it was based on a web survey of a video cartoon story, i.e. it used a visual priming technique. This avoided problems due to a misunderstanding of words or differences in individual capacity. Participants had to watch a video and then answer a questionnaire aimed at testing their environmental attitude and WTP. Besides testing for a priming effect, the study also aimed at verifying loss aversion and endowment effect (Kahneman and Tversky 1979). It tested all frames in terms of WTP so as to avoid bias induced by monetary assessments implied by the WTP and WTA framework (Irwin 1994).

The results showed that priming and its frame were the main variables determining differences between groups. In particular, they highlighted that while priming increased the likelihood of attention to the ethical and environmental characteristics of a good (smartphone), frames affected WTP a price premium for a smartphone with a higher level of recyclability. In other words, among people with pro-social traits, priming increased the probability that externalities became potentially relevant while framing raised the probability of making externalities Pareto-relevant. This finding is in line with those of other studies (e.g. Spence and Pidgeon 2010). Moreover, if one accepts our interpretation of urban and natural settings, it confirms the loss aversion and 
endowment effect. It is also consistent with the conditional cooperation hypothesis (Chaudhuri 2011; Fischbacher et al. 2001).

Our results have interesting policy implications. They show that people's awareness of the severity of environmental problems may be boosted by nudges. If appropriately primed, nudges also increase their willingness to help solve the problem. We can, therefore, expect a proper information campaign, based on non-technical tools, to complement other policies for developing more environmental consciousness in consumers and sustainable development.

However, our results suggest that nudging is effective when it occurs during the decision process. A tentative example of a policy measure exploiting this idea could be the introduction of a (compulsory) visual label on the shelves, indicating an environmental rating. When choosing a new item, such as a smartphone, the consumer receives many different stimuli (advertisements, fashion and social pressure, advice from friends, etc.). The label is an additional stimulus, reminding potential buyers of the ecological value of the good. In the sense of Thaler and Sunstein, this nudge (implicitly) enriches the consumer's information set and "forces" those with pro-social preferences to adjust their choice in order to maximize their utility. The label would reinforce consumers in their pro-environmental attitude and produce a double dividend: higher private utility and improved social welfare (better environmental quality).

These results are confirmed by the gender and education effect. Many studies have shown that women have more pro-social preferences, while education has been widely considered a determinant of individual environmental awareness. Our experiment confirmed both these aspects since gender and higher education reinforced the priming effect.

Our results also suggest that a positively framed stimulus is far more effective than a negatively framed one. This means that any public campaign should not just stress the negative features of a polluted world. Our results indicate that it is more effective to stress and emphasize what people risk losing if they do not change their behavior, presenting the problem in a positive frame. Such campaigns should also emphasize that many people are working to solve environmental problems and that good practices are happening in society: in this way, they do not discourage conditional cooperators from making their contribution.

Although interesting, our study is not without its limitations, some common to other such studies. The first is the representativeness of the sample obtained by a web survey. Our average subject was young, educated, willing and able to use social media, and therefore not the average Italian citizen. It would, however, be unfair to say that our results have no value. They can be seen as a step in a new direction.

Another aspect worth noting concerns the survey technique. The experiment used a stated preference approach. As we know, differences may arise between stated and actual behavior (revealed preferences). Stated preference is a survey-based technique often used for establishing valuations (contingent valuation). It may give rise to problems, such as the respondent being deliberately misleading for reputational effect (wanting to appear in a positive light); as well, people often have a poor understanding of what they are asked to value. In our opinion, however, our method avoided both these problems, because the survey was anonymous and participants were "hidden" by the web. The nature of the visual stimulus was also very simple for people of any age and educational level to understand. Revealed preference techniques would naturally shed new light on the issue and ensure sounder results. The analysis in greater depth, 
involving a larger and more representative sample, would make it possible to infer more general results.

\section{Acknowledgements}

We are really in debt with Jacopo Minnucci for having assisted us in the web-based survey and drawn cartoons. His help improved a lot the quality of our research.

\section{Disclosure statement}

No potential conflict of interest was reported by the authors.

\section{References}

Akerlof, G. A., and R. E. Kranton. 2000. "Economics and Identity." Quarterly Journal of Economics 115 (3): 715-753. doi:10.1162/003355300554881.

Andersson, O., T. Miettinen, K. Hytönen, M. Johannesson, and U. Stephan. 2017. "Subliminal Influence on Generosity.” Experimental Economics 20 (3): 531-555. doi:10.1007/s10683016-9498-8.

Andreoni, J. 1995. "Warm-Glow versus Cold-Prickle: The Effects of Positive and Negative Framing on Cooperation in Experiments." Quarterly Journal of Economics 110 (1): 1-21. doi: $10.2307 / 2118508$.

Banks, S. M., P. Salovey, S. Greener, A. J. Rothman, A. Moyer, J. Beauvais, and E. Epel. 1995. "The Effects of Message Framing on Mammography Utilization." Health Psychology 14 (2): 178-184. doi:10.1037/0278-6133.14.2.178.

Bargh, J. A. 2006. "What Have We Been Priming All These Years? On the Development, Mechanisms, and Ecology of Nonconscious Social Behavior.” European Journal of Social Psychology 36 (2): 147-168. doi:10.1002/ejsp.336.

Bargh, J. A., and T. L. Chartrand. 2014. "The Mind in the Middle." In Handbook of Research Methods in Social and Personality Psychology, edited by Reis, H.T. and C.M. Judd, 311-344. New York: Cambridge University Press.

Bargh, J. A., M. Chen, and L. Burrows. 1996. "Automaticity of Social Behavior: Direct Effects of Trait Construct and Stereotype Activation on Action." Journal of Personality and Social Psychology 71 (2): 230-244. doi:10.1037/0022-3514.71.2.230.

Bowles, S. 2016. The Moral Economy: Why Good Incentives Are No Substitute for Good Citizens, Why Good Incentives Are No Substitute for Good Citizens. New Haven and London: Yale University Press.

Bowles, S., and S. Polanía-Reyes. 2012. "Economic Incentives and Social Preferences: Substitutes or Complements?" Journal of Economic Literature 50 (2): 368-425. doi: 10.1257/jel.50.2.368.

Buchanan, J. M., and W. C. Stubblebine. 1962. "Externalities.” Economica 29 (116): 371-384. doi: $10.2307 / 2551386$.

Chaudhuri, A. 2011. "Sustaining Cooperation in Laboratory Public Goods Experiments: A Selective Survey of the Literature." Experimental Economics 14 (1):47-83. doi:10.1007/ s10683-010-9257-1.

Clarke, A., P. A. Bell, and G. L. Peterson. 1999. "The Influence of Attitude Priming and Social Responsibility on the Valuation of Environmental Public Goods Using Paired Comparisons." Environment and Behavior 31 (6):838-857. doi.org/10.1177/00139169921972371

Cohn, A., M. André, and M. Chal. 2016. "Priming in Economics." Current Opinion in Psychology 12:17-21. doi:10.1016/j.copsyc.2016.04.019.

Dennis, A. R., L. Yuan, C. J. Hsieh, X. Feng, A. P. Hedge, and E. M. Webb. 2015. "The Priming Effects of Relevant and Irrelevant Advertising in Online Auctions." Proceedings of the Annual Hawaii International Conference on System Sciences. 
Dietz, T., L. Kalof, and P. C. Stern. 2002. "Gender, Values, and Environmentalism." Social Science Quarterly 83 (1): 353-364. doi:10.1111/1540-6237.00088.

Edwards, A., G. Elwyn, J. Covey, E. Matthews, and R. Pill. 2001. "Presenting Risk Information-A Review of the Effects of 'Framing' and Other Manipulations on Patient Outcomes." Journal of Health Communication 6 (1): 61-82. doi:10.1080/ 10810730150501413.

Ekström, M. 2012. "Do Watching Eyes Affect Charitable Giving? Evidence from a Field Experiment." Experimental Economics 15 (3): 530-546. doi:10.1007/s10683-011-9312-6.

Fehr, E., and K. Hoff. 2011. "Introduction: Tastes, Castes and Culture: The Influence of Society on Preferences." The Economic Journal 121 (556): F396-F412. doi:10.1111/j.14680297.2011.02478.x.

Fischbacher, U., S. Gächter, and E. Fehr. 2001. "Are People Conditionally Cooperative? Evidence from a Public Goods Experiment." Economics Letters 71 (3): 397-404. doi: 10.1016/S0165-1765(01)00394-9.

Gifford, K., and J. C. Bernard. 2006. "Influencing Consumer Purchase Likelihood of Organic Food." International Journal of Consumer Studies 30 (2): 155-163. doi:10.1111/j.14706431.2005.00472.x.

Haley, K. J., and D. M. T. Fessler. 2005. "Nobody's Watching? Subtle Cues Affect Generosity an Anonymous Economic Game." Evolution and Human Behavior 26 (3): 245-256. doi: 10.1016/j.evolhumbehav.2005.01.002.

Hardin, G. 1968. "The Tragedy of the Commons. The Population Problem Has No Technical Solution: It Requires a Fundamental Extension in Morality." Science 162: 1243-1248. [Database] doi:10.1126/SCIENCE.162.3859.1243.

Irwin, J. R. 1994. "Buying/Selling Price Preference Reversals: Preference for Environmental Changes in Buying versus Selling Modes." Organizational Behavior and Human Decision Processes 60 (3): 431-457. doi:10.1006/obhd.1994.1093.

Kahneman, D. 2011. Thinking, Fast and Slow. New York: Farrar, Straus and Giroux.

Kahneman, D., and A. Tversky. 1979. "Prospect Theory: An Analysis of Decision under Risk." Econometrica 47 (2): 263-292. doi:10.2307/1914185.

Koçaş, C., and K. Dogerlioglu-Demir. 2014. "An Empirical Investigation of Consumers' Willingness-to-Pay and the Demand Function: The Cumulative Effect of Individual Differences in Anchored Willingness-to-Pay Responses.” Marketing Letters 25 (2): 139-152. doi:10.1007/s11002-013-9235-4.

Li, T., J. R. Fooks, and K. D. Messer. 2017. "Residents' Preferences in Adopting Water Runoff Management Practices: Examining the Effect of Behavioral Nudges in a Field Experiment." Selected Paper Prepared for Presentation at the Agricultural \& Applied Economics Association's 2017 AAEA Annual Meeting, Chicago, IL, July 30-August 1, 2017.

Long, J., and J. Freese. 2006. Regression Models for Categorical Dependent Variables Using Stata. College Station, TX: StataCorp LP.

Molden, D. 2014. "Understanding Priming Effects in Social Psychology: What Is "Social Priming" and How Does It Occur?" Social Cognition 32: 1-11. doi:10.1521/ soco.2014.32.supp.1.

Nettle, D., Z. Harper, A. Kidson, R. Stone, I. S. Penton-Voak, and M. Bateson. 2013. "The Watching Eyes Effect in the Dictator Game: It's Not How Much You Give, It's Being Seen to Give Something." Evolution and Human Behavior 34 (1): 35-40. doi:10.1016/ j.evolhumbehav.2012.08.004.

Rigdon, M., K. Ishii, M. Watabe, and S. Kitayama. 2009. "Minimal Social Cues in the Dictator Game.” Journal of Economic Psychology 30 (3): 358-367. doi:10.1016/j.joep.2009.02.002.

Rothman, A. J., R. D. Bartels, J. Wlaschin, and P. Salovey. 2006. "The Strategic Use of Gainand Loss-Framed Messages to Promote Healthy Behavior: How Theory Can Inform Practice." Journal of Communication 56 (Suppl. 1): S202-S220. doi:10.1111/j.14602466.2006.00290.x.

Sayman, S., and A. Öncüler. 2005. "Effects of Study Design Characteristics on the WTA-WTP Disparity: A Meta Analytical Framework." Journal of Economic Psychology 26 (2): 289-312. doi:10.1016/j.joep.2004.07.002.

Schorn, R., and B. Maurhart. 2009. "Influencing Willingness to Pay by Supraliminally Priming the Concept of Honesty." Advances in Consumer Research 36: 463-466. 


$$
\int_{0}
$$

